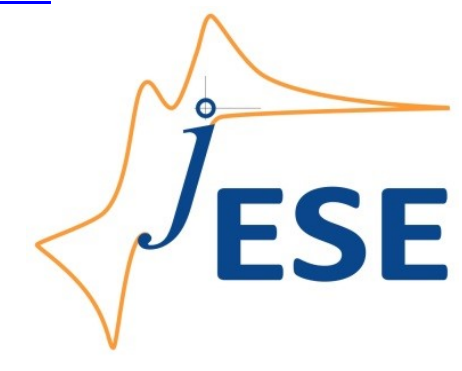

Open Access: ISSN 1847-9286

www.jESE-online.org

Original scientific paper

\title{
Effects of different factors on electrochemical obtaining of Re-Te-Cu alloys
}

\author{
Elza A. Salakhova ${ }^{\circledR}$, Dilgam B. Tagiyev, Parvana E. Kalantarova, Ramila E. Huseynova \\ and İrana İ. Cabbarova \\ Institute of Catalysis and Inorganic Chemistry of Azerbaijan National Academy of Sciences, AZ1143, \\ H. Javid Ave. 113, Baku, Azerbaijan
}

Corresponding author: ${ }^{\boxplus}$ elza salahova@mail.ru

Received: August 2, 2020; Revised: February 7, 2021; Accepted: February 15, 2021

\begin{abstract}
Based on the study of volt-ampere dependencies during electroreduction of rhenium (VII), tellurium (IV) and copper (II) ions from hydrochloric acid electrolyte on Pt electrode, the conditions of deposition of nano-coatings of ternary Re-Te-Cu alloy were determined. The influence of various factors such as amounts of individual components and total concentrations of components in the electrolyte solution, temperature, concentration of hydrochloric acid, etc., on the composition and quality of coatings was studied. It was established that with the increase of rhenium concentration in the electrolyte, as well as increase of temperature, the rhenium content in deposits increased. The morphology of films deposited on platinum substrate was studied using the scanning electron microscopy. Based on the experimental data, the following electrolyte composition (mol/l) is recommended for

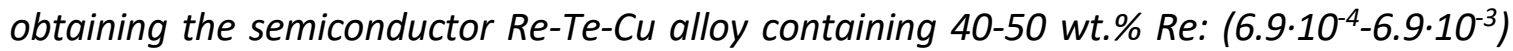
$\mathrm{KReO}_{4}+\left(9 \cdot 10^{-4}-1.8 \cdot 10^{-2}\right) \mathrm{TeO}_{2}+\left(6 \cdot 10^{-4}-1.2 \cdot 10^{-2}\right) \mathrm{CuCl}_{2} \cdot 2 \mathrm{H}_{2} \mathrm{O}+2 \mathrm{HCl}, \mathrm{T}=75{ }^{\circ} \mathrm{C}$.
\end{abstract}

\section{Keywords}

Rhenium alloys; ternary alloys; thin coatings; electrochemical deposition; electrolyte composition

\section{Introduction}

One of the most important tasks of metal science is to: a) study the structure and properties of refractory metals and alloys, b) develop technological schemes for obtaining pure refractory metals and metal products, and c) study their operational characteristics in various devices and tools. The general aim is to scale up the application of refractory metals and alloys, since materials (particularly refractory metals) often play a decisive role in the development of entire industries of new technology. Refractory metals have unique properties that make them indispensable in many 
aspects of new technology. They have high melting, boiling and recrystallization temperature as well as low vapor pressure, which all allow use of these metals for long-term operation at high temperatures in deep vacuum.

Rhenium (Re) is a heat-resistant metal that has widely been used as high-tech material with exceptional properties. This metal has some specific properties and is used in various fields of semiconductor industry for space technology, electronics, etc. Rhenium is an important component of heat-protection shields for reducing the temperature of objects returned from the space. Also, common filaments produced from tungsten coated with rhenium increase the service life of lamps, while very thin rhenium coatings are found highly effective for the corrosion protection of metals.

Rhenium chalcogenides are semiconductor materials, which can be used as photosensitive elements in the visible spectrum [1-5]. Rhenium alloys with sulfur are in the form of thin coatings used as photosensitive materials in the semiconductor engineering. Also, rhenium-sulfur alloys are frequently used as efficient catalysts in dehydrogenation of alcohols.

Various methods have already been used to produce thin films of semiconducting rhenium alloys. Analysis of all known methods of obtaining thin layers of rhenium chalcogenides showed clearly that the electrochemical method is the most promising and economical [6-12]. Therefore, the search and development of new electrochemistry related techniques to produce thin semiconductor films of rhenium chalcogenides on various substrates including metal substrates, is considered not only practically, but also theoretically relevant [13-18].

The present work is devoted to the electrochemical deposition of ternary semiconductor Re-CuTe coatings from hydrochloric acid electrolyte, and the study of the effects of various factors on the composition and quality of deposited ternary alloys.

\section{Experimental}

Polarization curves were measured in a glass cell equipped with $50 \mathrm{ml}$ of glass jacket. Polarization measurements were carried out with platinum electrode having the surface of $0.15 \mathrm{~cm}^{2}$, welded to a glass tube. Silver/silver-chloride electrode $(\mathrm{Ag} / \mathrm{AgCl})$ was used for polarization measurements as the reference electrode. Platinum plate with the surface area of $2.0 \mathrm{~cm}^{2}$, having thus several times higher area then the working electrode, was used as the counter electrode. With the aim of studying the kinetics of co-electrodeposition of rhenium with some chalcogens, the method of cyclic voltammetry was applied using IviumStat. For the composition analysis, co-electrodeposition was performed on $\mathrm{Pt}$ substrate with the surface area of $2.0 \mathrm{~cm}^{2}$ under galvanostatic conditions. For the structure, morphology and elemental analyses, co-electrodeposition under potentiostatic conditions was performed. Deposition time ranged from 30 to $60 \mathrm{~min}$. To check the scientific reproducibility, each experiment was performed twice. The working temperature for electrodeposition was $75{ }^{\circ} \mathrm{C}$, except for experiments when the effect of temperature was followed. Temperature was regulated with the accuracy of $\pm 0.1^{\circ} \mathrm{C}$ using U-10 thermostat. Morphologies of deposited films and electrode surfaces were studied using JEOL JSM7600F scanning electron microscope (SEM) at various magnifications, while the elemental analysis was carried out using Oxford X-MAX 50 detector (EDS). The sample was scanned in secondary electron mode at an acceleration voltage of $\sim 15 \mathrm{keV}$. X-ray diffraction analysis of films was performed using DRON-5 at Cu K $\alpha$-radiation. The amount of copper was determined separately by an atomic-absorption spectrophotometer AAS-1N Carl Zeiss Jena. The amounts of rhenium and tellurium were determined separately by thiourea complex, using colorimetric method on SPECORD 50 PLUS. Current output was detected with copper coulombmeter by weighing method and was calculated with regard to the composition of deposit. $\mathrm{pH}$ of solutions was determined at $\mathrm{pH} / \mathrm{mV} / \mathrm{Temp} \mathrm{AZ} 86551$. The composition of 
$\mathrm{Re}-\mathrm{Te}-\mathrm{Cu}$ alloy was analyzed as follows: firstly, the electrochemically obtained cathode deposit was heated and dissolved in $10 \mathrm{ml}$ of nitric acid, and after vaporizing several times in water steam, $5 \mathrm{~N}$ $\mathrm{NH}_{3} \mathrm{PO}_{4}$ is added. Then, rhenium was separated from tellurium and copper by extracting with isoamyl alcohol. When both Te and Re were separated, they are determined at SPECORD 50 PLUS using spectrophotometric method. Determination of copper in Re-Te-Cu system was conducted at AA $280 \mathrm{FS}$ FAST sequential atomic absorption spectrometer Varian.

\section{Results and discussion}

To study the co-deposition of rhenium, tellurium and copper, the deposition processes of these metals from a chosen electrolyte must be studied separately. For this purpose, electrolytic depositions of rhenium, tellurium and copper from $2 \mathrm{M} \mathrm{HCl}$ solution were studied by cyclic voltammetry (CV) technique.

In chloride electrolyte, rhenium is present in the form of perrhenate, $\mathrm{ReO}_{4}^{-}$(VII), ions and reduction of rhenium is proceding in several stages [7-10]. It is seen in Figure 1(a) that at potentials preceeding hydrogen evolution reaction, the reduction of $\mathrm{ReO}_{4}{ }^{-}$ions in the strong acidic electrolyte goes in stages. Reduction in a order $\operatorname{Re}(\mathrm{VII}) \rightarrow \operatorname{Re}(\mathrm{VI}) \rightarrow \operatorname{Re}(\mathrm{IV}) \rightarrow \operatorname{Re}(0)$ leads to the formation of intermediate oxide layers, what is confirmed by X-ray analysis and red and blue colors in deposits. By studying the effects of the concentration of rhenium, temperature of electrolyte, and concentration of $\mathrm{HCl}$ solution, the optimum conditions were selected for obtaining high-quality rhenium deposits from chloride electrolyte.

Electrolytic deposition process of tellurium from $2 \mathrm{M} \mathrm{HCl}$ solution was also studied by cyclic voltammetry, and typical CV curve is shown in Figure 1(b). Optimum conditions for deposition of tellurium from $\mathrm{HCl}$ solution were determined by studying effects of concentration of tellurium, and temperature on polarization curves. Reduction of tellurium ions is proceeding according to the following way: the first stage of reduction process is determined by formation of elementary tellurium $\mathrm{Te}(0)$ from $\mathrm{HTeO}_{2}{ }^{+}(\mathrm{IV})$ ions present in highly acid electrolyte. In the second stage, divalent tellurium $\left(\mathrm{Te}_{2}\right)^{-2}(-\mathrm{II})$ is formed, while in the third stage of electrode process, the formation of hydrogen was observed. In the reverse scan, a peak at about $0.3 \mathrm{~V}$ denotes anodic dissolution of the formed tellurim film.

Cyclic polarization curve presented in Figure 1(c) shows the reduction process of copper ions at the cathode. Optimum conditions for deposition of copper were determined by studying the effects of copper ion concentration in the electrolyte, temperature, and acidity of electrolyte. Stepwise reduction of $\mathrm{Cu}(\mathrm{II}) \rightarrow \mathrm{Cu}(0)$ is observed before hydrogen evolution reaction, what is probably due to the slowness of $\mathrm{Cu}(\mathrm{II}) \rightarrow \mathrm{Cu}(\mathrm{I})$ step caused by stable $\mathrm{Cu}(\mathrm{II}) \mathrm{Cl}_{\mathrm{x}}$ complexes formed in chloride solutions. One stripping wave is observed in the anodic curve of copper at $-0.05 \mathrm{~V}$ due to oxidation of copper.

To study co-deposition of Re-Te-Cu components, an electrolyte containing all three components was used, and polarization curves of co-deposition are plotted in Figure 1(d). When observing polarizarion curves of Re-Cu-Te in Figure 1(d), one can clearly see three anodic stripping waves. Wave I in anodic curve can be related to oxidation of $\mathrm{Cu}$, wave II to oxidation of $\mathrm{Te}$, and wave III to anodic dissolution of new triple Re-Te-Cu alloy film.

In order to obtain thin semiconductor coatings of rhenium-copper-tellurium alloy from chloride electrolyte and to find optimal conditions for co-deposition, effects of various factors were studied: concentrations of components, temperature, current density of deposition, and concentration of $\mathrm{HCl}$ solution. As was expected, the composition and quality of Re-Cu-Te alloy films are highly affected by rhenium content in the electrolyte (Table 1 ). 
a

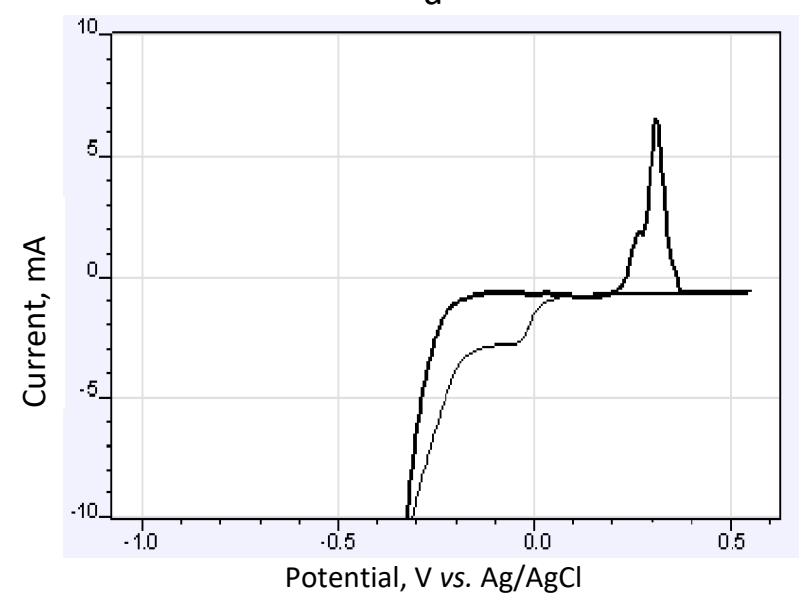

C

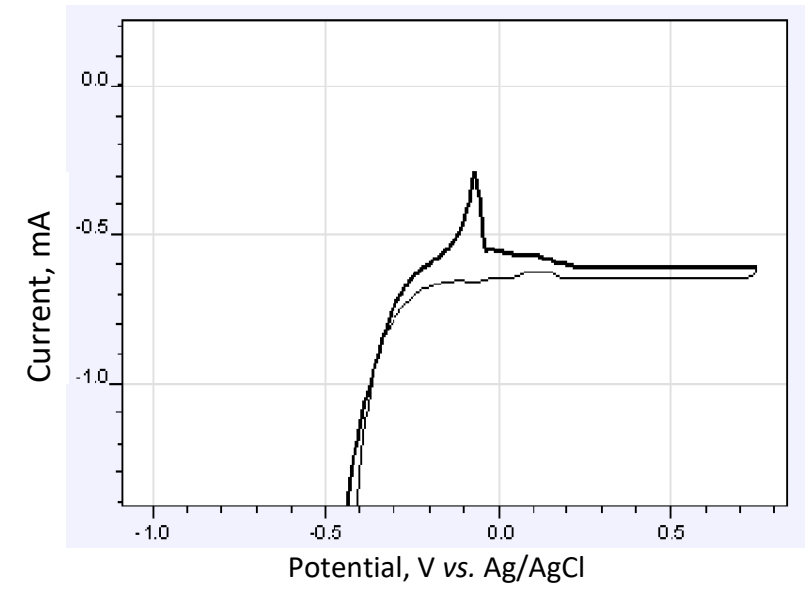

b

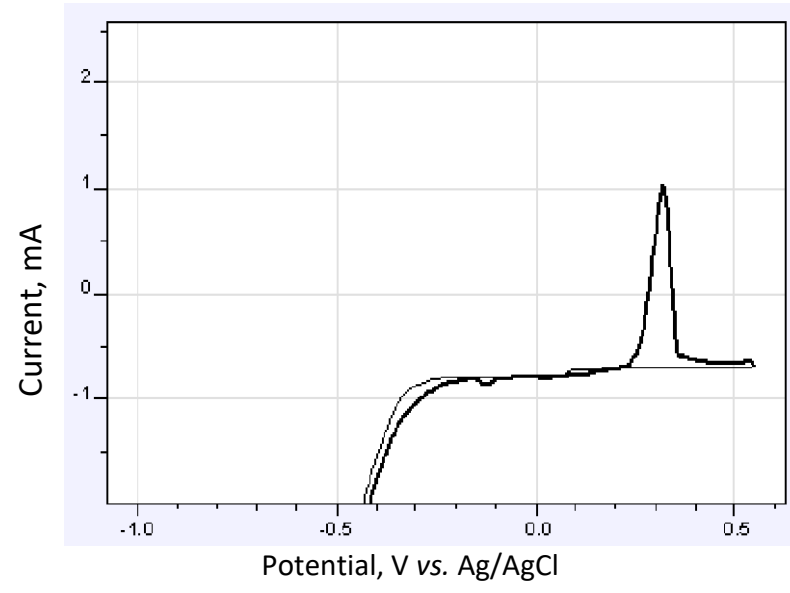

d

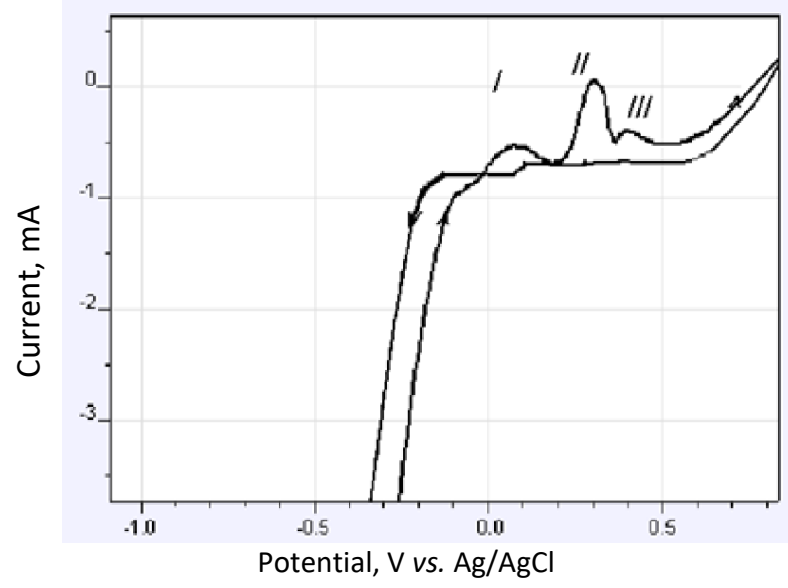

Figure 1. Cyclic polarizing curve (0.005 $\left.\mathrm{Vs}^{-1}\right)$ of rhenium (a), tellurium (b), copper (c), rhenium-tellurium-copper (d) on Pt electrode in the electrolyte containing (mol/l):

(a) $6.9 \cdot 10^{-3} \mathrm{KReO}_{4}+2 \mathrm{HCl}$; (b) $1.8 \cdot 10^{-2} \mathrm{TeO}_{2}+2 \mathrm{HCl}$; (c) $1.2 \cdot 10^{-2} \mathrm{CuCl}_{2} \cdot 2 \mathrm{H}_{2} \mathrm{O}+2 \mathrm{HCl}$;

(d) $6.9 \cdot 10^{-3} \mathrm{KReO}_{4}+1.8 \cdot 10^{-2} \mathrm{TeO}_{2}+1.2 \cdot 10^{-2} \mathrm{CuCl}_{2} \cdot 2 \mathrm{H}_{2} \mathrm{O}+2 \mathrm{HCl} ; \mathrm{T}=75^{\circ} \mathrm{C}$

Table 1. Composition of Re-Cu-Te alloy films deposited on Pt electrode from $2 \mathrm{M} \mathrm{HCl}$ containing different concentrations of rhenium and constant concentrations of copper and tellurium. T = $75{ }^{\circ} \mathrm{C}, \mathrm{i}_{\mathrm{k}}=20 \mathrm{~mA} \mathrm{~cm}{ }^{-2}$

\begin{tabular}{ccccccc}
\hline \multicolumn{2}{c}{ Electrolyte concentration, $\mathrm{mmol} \mathrm{I}^{-1}$} & \multicolumn{3}{c}{ Content, wt.\% } & \multirow{2}{*}{ Appearance of coating } \\
\cline { 1 - 5 } $\mathrm{KReO}_{4}$ & $\mathrm{CuCl}_{2}$ & $\mathrm{TeO}_{2}$ & $\mathrm{Re}$ & $\mathrm{Te}$ & $\mathrm{Cu}$ & \\
\cline { 1 - 5 } 0.2 & 1.5 & 1.23 & 40 & 33 & 27 & Dark-gray, matte \\
\hline 0.6 & 1.5 & 1.23 & 42 & 32 & 26 & Dark-gray, matte \\
\hline 1.0 & 1.5 & 1.23 & 44 & 31 & 25 & Black, shiny \\
\hline 1.4 & 1.5 & 1.23 & 46 & 30 & 24 & Black, shiny \\
\hline 1.5 & 1.5 & 1.23 & 49 & 24 & 26 & Black, shiny \\
\hline
\end{tabular}

It was also established that at higher content of rhenium in the electrolyte, the rhenium content in the alloy increased with an increase of the electrolyte temperature (Table 2). High quality deposit coatings in the form of thin films are obtained at $75-80^{\circ} \mathrm{C}$. At $25-45^{\circ} \mathrm{C}$, however, Re-Cu-Te alloy with an excess of amorphous tellurium was obtained on the cathode, while at the temperature above 80 ${ }^{\circ} \mathrm{C}$, the quality of deposits deteriorates. Therefore, all experiments were performed at $75-80{ }^{\circ} \mathrm{C}$.

The effect of deposition current density on the composition and quality of Re-Cu-Te alloy deposits was studied at $75{ }^{\circ} \mathrm{C}$ on Pt cathode (Table 3). As the current density of deposition increased, the rhenium content in the alloy increased from 40 to $50 \mathrm{wt} . \%$. This can be explained by the fact that as the current density increases, the reduction of rhenium accelerates compared with the reduction of tellurium, and therefore the rhenium content in the alloy increases. 
Table 2. Composition of Re-Cu-Te alloy films deposited on Pt electrode $\left(i_{k}=20 \mathrm{~mA} / \mathrm{cm}^{2}\right)$ from $2 \mathrm{M} \mathrm{HCl}$ containing constant concentrations of rhenium, copper, and tellurium at different temperatures

\begin{tabular}{|c|c|c|c|c|c|c|c|}
\hline \multicolumn{3}{|c|}{ Electrolyte concentration, $\mathrm{mmol} \mathrm{I}^{-1}$} & \multirow{2}{*}{ Temperature, ${ }^{\circ} \mathrm{C}$} & \multicolumn{3}{|c|}{ Content, wt.\% } & \multirow{2}{*}{$\begin{array}{l}\text { Appearance of } \\
\text { coating }\end{array}$} \\
\hline $\mathrm{KReO}_{4}$ & $\mathrm{CuCl}_{2}$ & $\mathrm{TeO}_{2}$ & & $\operatorname{Re}$ & $\mathrm{Te}$ & $\mathrm{Cu}$ & \\
\hline 1.4 & 1.5 & 1.23 & 25 & 42 & 30 & 28 & dark-gray, matte \\
\hline 1.4 & 1.5 & 1.23 & 45 & 44 & 32 & 24 & dark-gray, matte \\
\hline 1.4 & 1.5 & 1.23 & 65 & 45 & 31 & 24 & black, shiny \\
\hline 1.4 & 1.5 & 1.23 & 75 & 46 & 30 & 24 & black, shiny \\
\hline 1.4 & 1.5 & 1.23 & 90 & 48 & 26 & 26 & black, shiny \\
\hline
\end{tabular}

Table 3. Composition of Re-Cu-Te alloy films deposited on Pt electrode from $2 \mathrm{M} \mathrm{HCl}$ containing constant concentrations of rhenium, copper, and tellurium at different deposition current densities. $\mathrm{T}=75^{\circ} \mathrm{C}$; $\mathrm{C}_{\mathrm{KReO}_{4}}=1.4 \mathrm{mmol} \mathrm{l}^{-1} ; \mathrm{CCuCl}_{2}=1.5 \mathrm{mmol} \mathrm{l}^{-1} ; \mathrm{C}_{\mathrm{TeO}_{2}}=1.23 \mathrm{mmol}^{-1}$

\begin{tabular}{ccccc}
\hline \multirow{2}{*}{$i_{\mathrm{k}} / \mathrm{mA} \mathrm{cm}^{-2}$} & \multicolumn{3}{c}{ Content, wt.\% } & Appearance of coating \\
\cline { 2 - 4 } & $\mathrm{Re}$ & $\mathrm{Te}$ & $\mathrm{Cu}$ & Dark-gray, matte \\
\hline 5 & 42 & 30 & 28 & Dark-gray, matte \\
\hline 10 & 44 & 32 & 24 & black, shiny \\
\hline 15 & 45 & 31 & 24 & black, shiny \\
\hline 20 & 46 & 30 & 24 & black, shiny \\
\hline 25 & 47 & 27 & 26 &
\end{tabular}

The effect of $\mathrm{HCl}$ solution concentration on the composition and quality of Re-Cu-Te alloys was also studied (Table 4). Since Re-Cu-Te alloy film is deposited from an acidic electrolyte, the effect of acid concentration on the composition and quality of alloys has its importance. The composition of Re-Cu-Te cathode deposit is also highly dependent on the concentration of the acid in electrolyte. With the increase of $\mathrm{HCl}$ concentration in electrolyte, rhenium content in the alloy increases, but tellurium content decreases.

Table 4. Composition of Re-Cu-Te alloy films deposited on Pt electrode $\left(\mathrm{i}_{K}=20 \mathrm{~mA} / \mathrm{cm}^{2}\right)$ from different concentrations of $\mathrm{HCl}$ containing constant concentrations of rhenium, copper, and tellurium $\mathrm{T}=75{ }^{\circ} \mathrm{C}$; $\mathrm{C}_{K_{R e O}}=1.4 \mathrm{mmol}^{-1} ; \mathrm{CCuCl}_{2}=1.5 \mathrm{mmol}^{-1} ; \mathrm{C}_{\mathrm{TeO}_{2}}=1.23 \mathrm{mmol}^{-1}$

\begin{tabular}{ccccc}
\hline \multirow{2}{*}{$\mathrm{CHCl}_{\mathrm{HCl}} / \mathrm{mol} \mathrm{I}^{-1}$} & \multicolumn{3}{c}{ Content, wt.\% } & \multirow{2}{*}{ Appearance of coating } \\
\cline { 2 - 4 } & $\mathrm{Re}$ & $\mathrm{Te}$ & $\mathrm{Cu}$ & Dark-gray, matte \\
\hline 1.0 & 42 & 30 & 28 & Dark-gray, matte \\
\hline 1.5 & 44 & 30 & 26 & black, shiny \\
\hline 2.0 & 46 & 30 & 24 & black, shiny \\
\hline 2.5 & 47 & 28 & 25 & black, shiny \\
\hline 3.0 & 48 & 26 & 26 &
\end{tabular}

Morphologies of Re-Cu-Te films deposited on platinum substrates were studied by a scanning electron microscope. It was established generally that depending on the material of substrate, thin coatings with different compositions and sizes were obtained on the cathode when prepared at the same experimental conditions. However, coatings with grain sizes of 80-150 nm were obtained on Pt substrate electrode. SEM image and elemental composition of Re-Cu-Te film deposited on Pt substrate are shown in Figures 2 and 3.

Upon thorough investigation, a structure similar to nanostructure and formation of nanosized islets on a platinum sample is observed. Islets do not have a certain shape; they have forms of an egg, ellipse, and various other shapes.

X-ray pattern of Re-Cu-Te thin film deposited on Pt electrode and annealed at $500{ }^{\circ} \mathrm{C}$ for 2 hours is presented in Figure 4. 


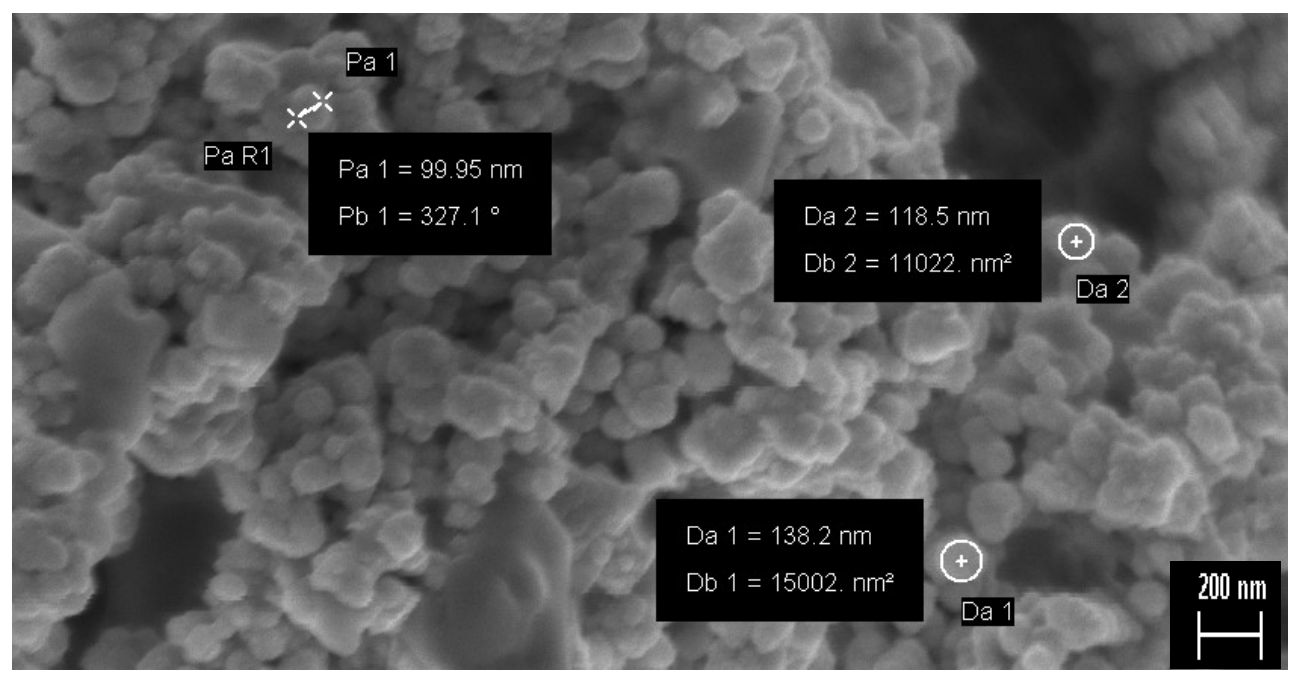

Figure 2. SEM image Re-Te-Cu thin film deposited on Pt substrate

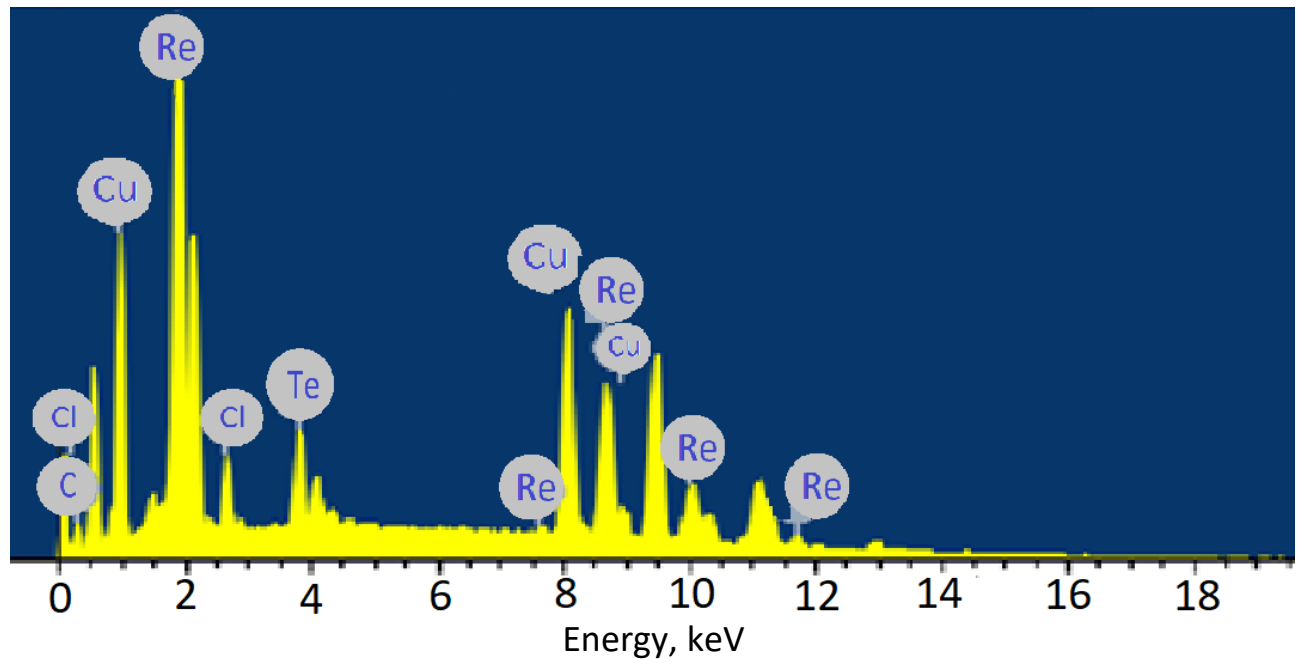

Figure 3. Elemental analysis of Re-Te-Cu thin film deposited on Pt electrode

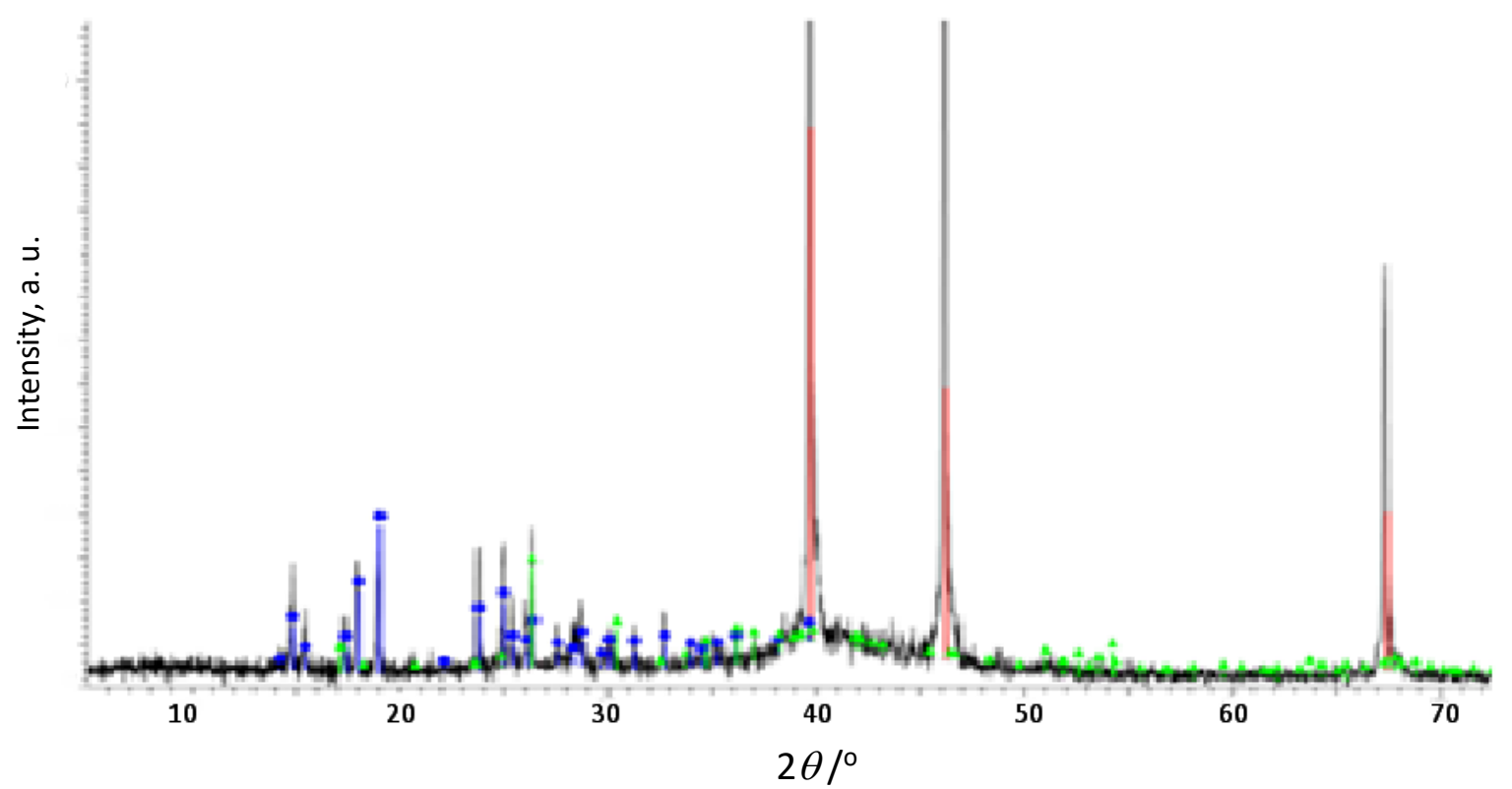

Figure 4. X-ray pattern of deposited Re-Cu-Te thin film annealed at $500{ }^{\circ} \mathrm{C}$ for 2 hours

It was found that depending on the electrolyte composition and current density during electrolysis, the substances comprising one and two phases are obtained. At optimum deposition conditions, the 
obtained Re-Te-Cu thin films on a platinum electrode contains oxide compounds. To purify the composition of films from various oxides, the substances obtained electrochemically in Re-Te-Cu system were annealed at $500{ }^{\circ} \mathrm{C}$ for 2 hours and an X-ray pattern was recorded. Intensity of the peaks becomes much more visible after annealing. This may be due to annealing of oxides in films.

\section{Conclusions}

Based on the study of volt-ampere dependencies during co-electroreduction of rhenium (VII), tellurium (IV) and copper (II) ions from chloride electrolytes on Pt electrode, the conditions of deposition of nano-coatings of ternary Re-Te-Cu alloy system were determined.

The influence of various factors on the composition and quality of coatings was studied. These factors were concentrations of individual components and total concentration of components in the electrolyte, temperature of electrolyte, current density of deposition and concentration of $\mathrm{HCl}$ solution.

It was established that with the increase of rhenium content in the electrolyte and temperature, the rhenium content in deposits increases. Based on the experimental data, the following electrolyte composition was recommended for obtaining the semiconductor Re-Te-Cu alloy on Pt electrode in the electrolyte solution containing 40-50 wt.\% of Re: $\left(6.9 \cdot 10^{-4}-6.9 \cdot 10^{-3}\right) \mathrm{M} \mathrm{KReO}_{4}+\left(9 \cdot 10^{-4}-1.8 \cdot 10^{-2}\right) \mathrm{M} \mathrm{TeO}_{2}$ $+\left(6 \cdot 10^{-4}-1.2 \cdot 10^{-2}\right) \mathrm{M} \mathrm{CuCl}_{2} \cdot 2 \mathrm{H}_{2} \mathrm{O},+2 \mathrm{M} \mathrm{HCl} . \mathrm{T}=75^{\circ} \mathrm{C}$.

The morphology of films deposited on Pt substrate electrode is followed by the scanning electron microscope, showing formation of nanosized islets with grain sizes of $80-150 \mathrm{~nm}$.

\section{References}

[1] E. F. Speranskaya, Electrochemistry of Rhenium, Gylym, Alma-Ata, 1990. p. 253. (In Russian)

[2] A. Naor, N. Eliaz, E. Gileadi, R. Taylor, The AMMTIAC Quarterly 5(1) (2010) 11-15 http://dx.doi.org/10.4236/jmmce.2013.15032.

[3] A. A. Pallant, Monograph Metallurgy of Rhenium. Nauka, Moscow, 2007. p. 298. (in Russian)

[4] A. N. Enyashin, I. Popov, Physica Status Solidi (b) 246(1) (2009) 114-118 https://doi.org/10.1002/pssb. 200844254.

[5] O. Berkh, N. Eliaz, E. Gileadi, Journal of the Electrochemical Society 161(5) (2014) D219-D226 https://doi.org/10.1149/2.038405jes.

[6] T. G. Gray, C. M. Rudzinski, E. E. Meyer, D. G. Nocera, The Journal of Physical Chemistry A 108(16) (2004) 3238-3243 https://doi.org/10.1021/jp0358937.

[7] A. Naor, N. Eliaz, E. Gileadi, Journal of the Electrochemical Society 157(7) (2010) D422-D427 https://doi.org/10.1149/1.3430084.

[8] A. Ye. Novikov, A. S. Shmygalev, A. V. Isakov, Y. P. Zaykov, International Journal of Electrochemical Science 14 (2019) 1145611464 https://doi.org/10.20964/2019.12.17.

[9] A. Chernyshev, A. Ye. Novikov, S. Shmygalev, A. V. Isakov, Y. P. Zaykov, International Journal of Electrochemical Science 14 (2019) 1145611464 https://doi.org/10.20964/2019.12.17.

[10] E. A. Salakhova, The Journal "Inorganic Materials" 39 (2003) 99-103 https://doi.org/10.1023/A:1022178109180.

[11] E. A. Salakhova, V. A. Majidzada, Russian Journal of Electrochemistry 47(8) (2011) 877-882 https://doi.org/10.1134/S1023193511080118.

[12] E. A. Salakhova, A. M. Aliyev, Advances in Materials Physics and Chemistry 2(4B) (2012) 253-255 https://doi.org/10.4236/ampc.2012.24B064.

[13] E. A. Salakhova, A. M. Aliyev, K. F. Ibraghimova, American Chemical Science Journal 4(3) (2014) 337 347 https://doi.org/10.9734/ACSJ/2014/5878.

[14] E. A. Salakhova, D. B. Tagiyev, P. E. Kalantarova, K. F. Ibrahimova, Journal of Materials Science and Chemical Engineering 3 (2015) 82-87 http://dx.doi.org/10.4236/msce.2015.311010.

[15] E. A. Salakhova, D. B. Tagiyev, K. F. Ibrahimova, P. E. Kalantarova, Journal of Materials Science and Chemical Engineering 3 (2015) 1-8 http://dx.doi.org/10.4236/msce.2015.310001. 
[16] E. A. Salakhova, D. B. Tagiyev, P. E. Kalantarova, K. F. Ibrahimova, International Journal of Current Research 9(1) (2017) 45406-45411 http://www.journalcra.com.

[17] S. De, W. D. Sides, T. Brusuelas, Q. Huang, Journal of Electroanalytical Chemistry 860 (2020) 113889 https://doi.org/10.1016/j.jelechem.2020.113889.

[18] B. P. Hahn, K. J. Stevenson, Electrochimica Acta 55(22) (2010) 6917-6925 https://doi.org/10.1016/j.electacta.2010.05.001.

(C)2021 by the authors; licensee IAPC, Zagreb, Croatia. This article is an open-access article distributed under the terms and conditions of the Creative Commons Attribution license (https://creativecommons.org/licenses/by/4.0/) 